UC-NRLF

||||||||||||||||||||||||||||||||||||||||||||||||||

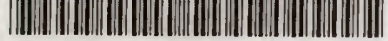

В 4 501 289 


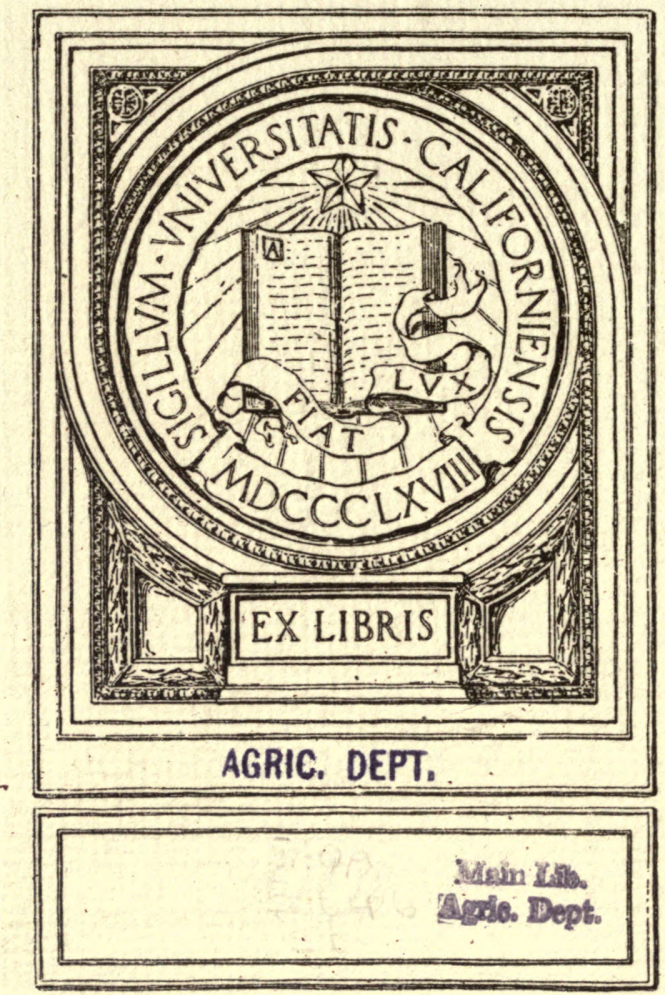







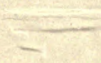

is

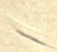




\section{Studies on Hybrid Ducks}

H. D. GOODALE

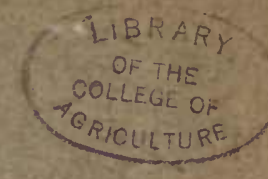

Reprinted from The Jodrnal of Experimental ZoöLoGY, Vol. 10, No. 3, April, 1911 



\title{
STUDIES ON HYBRID DUCKS
}

\author{
H. D. GOODALE
}

NINE FIGURES

TWO PLATES

As no studies from a Mendelian standpoint seem to have been made on ducks, the following experiments were undertaken. The results thus far obtained are sufficiently interesting and suggestive to make a first report on the work in progress desirable. The record shows that too few individuals in the $F_{1}$ generation have been reared to make much theoretical discussion profitable.

My thanks are due Mr. B. B. Horton for permitting me to carry on this work at "Oakwood."

\section{DESCRIPTION OF BREEDS}

The two breeds used, which were crossed reciprocally, were the Pekins and Rouens. It is well known that both varieties breed true. Some 200 of the former and 40 of the latter have been reared, and without exception have been true to type.

The Pekins (fig. 1) are white with yellow bills. The shanks and feet are orange. The ducklings are yellow throughout.

The Rouens are practically domesticated Mallards. The male (fig. 2) is brilliantly colored. His head and the upper half of the neck is deep lustrous green, bounded on its lower edge with a narrow white ring, often incomplete dorsally. The ventral side of the lower half of the neck, together with the breast (i.e., anterior to keel) is a deep claret (maroon). The remainder of the ventral surface is iron gray, becoming black posterior to the anus. The entire dorsal surface, posterior to the neck ring, is dark, being dull brownish anteriorly, becoming black in the 


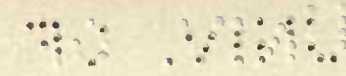

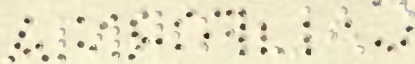

middle of the back, and greenish black on the rump. All the gray feathers, scapulars, and the anterior dorsal feathers are vermiculated. The main tail feathers are dull black. A speculum of iridescent purple is formed by the major part of the exposed surface of the secondaries. The under side of the wing, not including the remiges, is creamy white. The bill is light greenish yellow. The shanks and feet are orange. The female, (fig. 3), by contrast, is rather plain colored. On the whole she may be described as streaked dark brown and buff. The upper surface is considerably darker than the ventral. The throat and sides of the head are buff with two dark stripes passing across the latter (fig.4A). There is no neck ring. The speculum and under surface of the wing are the same as in the male. The bill is dull brownish black, with greenish yellow blotches. The shanks and feet are orange. The newly hatched Rouen duckling of both sexes is dull black with two dull yellow stripes on each side of the head and with some dull yellow spots on the body.

\section{THE $F_{1}$ GENERATION}

Owing to the method of making the matings the individual mothers of the $F_{1}$ generation are not known. A Rouen male was placed in a pen of Pekin females and vice versa. There were 23 young hatched from both matings, 13 were hatched here in 1909; 6 had Rouen mothers, 7 Pekin. The other 10, all Pekin males by Rouen females, were hatched and reared for me by my brother in 1910. Their parents were from my own stock. Of these I personally saw only 5 females as adults. Besides these there were nearly a dozen others from the same matings, but in which the ducklings from the reciprocal crosses were mixed together owing to an oversight at hatching time.

$F_{1}$ ducklings. Part of the $\mathrm{F}_{1}$ ducklings belonged to the Rouen type. The remainder had a new type of down. These were dull yellow, very different from the Pekin color, and with an under color of dull black which usually came to the surface on the wings and tail. This type probably represents an incomplete dominance of the Rouen down over the Pekin. The only exceptions to these 
forms were two black ducklings which appeared among the dozen mentioned above.

$F_{1}$ adults. From the mating Rouen female and Pekin male, seven females and five males grew to maturity. From the reciprocal mating there were two females and three males. These were all pigmented and on the whole closely resembled the Rouens. When, however, the various characters were considered separately it was found that the hybrids differed in several points from the Rouens, as will appear from the following description. Besides these there were two greenish black females with white throats and breasts (fig. 7). They appeared among the lot of hybrids in which the reciprocal crosses were mixed.

The males (fig. 5), generally speaking, are all alike, such variation as was noted being one of degree rather than kind. The head is identical with that of the male Rouen. The rest of the body is usually somewhat lighter in tone, so that the hybrids appear brighter than the Rouen male. There is a neck ring, several times as broad as that of the Rouen in all the males. The claret feathers of the breast are partly white, especially in the midline. On the other hand, the feathers of the dorsal side of the lower neck contain much claret. The dorsal surface of the wing usually is quite different from the Rouen. The anterior third is nearly white, due to the presence of a broad white margin to each feather. The next three rows or thereabouts have less white, but present a broad submarginal band of rufous, which becomes less conspicuous in the next two rows. The next row, which lies directly over the remiges, is not especially modified. A variable number of the primaries are always white. The main tail feathers may have white or vermiculated margins. Vermiculations may also appear in sections where they do not occur in the pure Rouen. There is one male, however, in which the breast and the dorsal surface of the wing is the same as that of the thorough-bred Rouen. This may be merely a variation in dominance, or it may have greater significance.

The females (fig. 6), with the two exceptions already noted, are also brighter colored than the female Rouens, but not more so than what I am informed is the fancier's ideal. The brighter 
color is due to the presence on the feathers of more buff and less black than occurs in the Rouens as I have bred them. The most striking point about the females is that in respect to a given character they can be divided into two classes, viz., those with and those without the character. Some characters, e.g., neck ring, are present or absent in the female irrespective of the direction in which the cross was made. But the data at hand are insufficient to make a statement of any value regarding other characters studied. The important point at present is the existance of two classes of females, in respect to certain characters, while the males all fall into one class. Thus, while all the males have broad neck rings, only part of the $F_{1}$ females have any ring at all. Two of the females lack the head stripes (fig. 4B). In addition, there are the two black females. There appear

TABLE 1

$F_{2}$ pigmented males

\begin{tabular}{|c|c|c|c|c|c|}
\hline & \multicolumn{2}{|c|}{ NOT INCLUDING BLACK } & \multicolumn{3}{|c|}{ INCLUDING BLACK } \\
\hline & $\begin{array}{c}\text { Like Rouen } \\
\text { male }\end{array}$ & Modified & $\begin{array}{l}\text { Like Rouen } \\
\text { male }\end{array}$ & Modifiec & \\
\hline Head..$\ldots \ldots \ldots \ldots \ldots \ldots$ & 7 & 0 & 8 & 0 & \\
\hline Bill.................. & 7 & 0 & 8 & 0 & \\
\hline Chin spot $^{8} \ldots$. & $6^{1}$ & 0 & 7 & 0 & \\
\hline Neck ring .. & 7 & 0 & 7 & $1^{6}$ & \\
\hline Breast............... & 3 & $4^{2}$ & 3 & $4^{2}$ & $1^{5}$ \\
\hline Claret .............. & 6 & $1^{6}$ & 6 & $2^{6}$ & \\
\hline 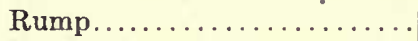 & 4 & $3^{2}$ & 5 & $3^{2}$ & \\
\hline Tail................ & 0 & $6^{2}$ & 1 & $6^{2}$ & \\
\hline Under tail coverts....... & 1 & $5^{2}$ & 2 & $5^{2}$ & \\
\hline Belly................ & 4 & $2^{2}$ & 4 & $3^{2}$ & \\
\hline Primaries............ & 0 & $6^{2}$ & 1 & $6^{2}$ & \\
\hline Upper surface of wing........ & 3 & $3^{2}$ & 3 & $3^{2}$ & $1^{7}$ \\
\hline Under surface of wing........ & 4 & $2^{3}$ & 4 & $3^{3}$ & \\
\hline Speculum............ & 4 & $2^{4}$ & 4 & $3^{4}$ & \\
\hline Legs and feet........ & 6 & 0 & 6 & $1^{2}$ & \\
\hline
\end{tabular}

${ }^{2}$ The difference in numbers is due to the lack of records on one male recorded simply as "like Rouen drake." $\quad 2$ With much white. $\quad{ }^{3}$ Pigmented. "Obscured. $\quad{ }^{5}$ Pure white. $\quad{ }^{6}$ Absent. $\quad{ }^{7}$ Black. $\quad{ }^{8}$ The chin spot is a small white spot at the base of the lower mandible. Among the pure Rouens I have seen it only in the males. $\quad{ }^{9}$ Black and orange. 
TABLE 2

$\mathrm{F}_{2}$ pigmented females

\begin{tabular}{|c|c|c|c|c|c|}
\hline & \multicolumn{2}{|c|}{ NOT INCLUDING BLACK } & \multicolumn{3}{|c|}{ INCLUDING BLACK } \\
\hline & $\begin{array}{l}\text { Like Rouen } \\
\text { female }\end{array}$ & Modified & $\begin{array}{l}\text { Like Rouen } \\
\text { female }\end{array}$ & Modifie & \\
\hline Head....... & 9 & $2^{1}$ & 9 & $2^{1}$ & $2^{8}$ \\
\hline Bill......... & 9 & $2^{2}$ & 11 & $2^{2}$ & \\
\hline Chin spot ......... & 6 & $5^{3}$ & 6 & $7^{3}$ & \\
\hline Neck ring......... & 5 & $6^{3}$ & 7 & $6^{3}$ & \\
\hline Breast.......... & 10 & $1^{4}$ & 10 & $1^{4}$ & $2^{9}$ \\
\hline Belly........... & 7 & $4^{4}$ & 7 & $5^{4}$ & $1^{8}$ \\
\hline Primaries........... & 4 & $7^{4}$ & 4 & $9^{4}$ & \\
\hline Upper surface of wing......... & 8 & $3^{4}$ & 8 & $3^{4}$ & $2^{8}$ \\
\hline Under surface of wing.... & 9 & $2^{5}$ & 9 & $4^{6}$ & \\
\hline Speculum.............. & 9 & $2^{6}$ & 9 & $4^{6}$ & \\
\hline 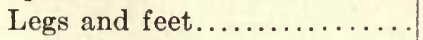 & 7 & $4^{7}$ & 7 & $4^{7}$ & $2^{10}$ \\
\hline
\end{tabular}

${ }^{1}$ Plain. ${ }^{2}$ Nearly yellow. ${ }^{3}$ Present. ${ }^{4}$ With much white. ${ }^{8}$ Pigmented. $\quad{ }^{6}$ Obscured. $\quad{ }^{7}$ With some black. ${ }^{8}$ Black. ${ }^{9}$ Pure white 10 Black and orange.

also to be several other characters which are present in part of the females and absent in the remainder, but which are either always present or always absent in the male. I am not prepared at present to speak definitely in regard to these characters mainly because this peculiarity in their inheritance was not noticed until the $\mathrm{F}_{2}$ generation was studied (tables 1 and 2). On the other hand, there are characters which are in only part of the individuals, of each sex. Thus, white shading on the breast and the white-red dorsal wing surface, as described for all but one of the $F_{1}$ males, are present in only part of the females. But I have failed to find any character, which is present in only part of the males, but which is always present or always absent in all the females. The significance of these statements will be considered later on in the paper.

The two greenish black individuals (fig. 7) with white throats and breasts resemble strongly the variety of ducks known as Blue Swedish. One died at an early age. The other shows 
traces of light head stripes. She has some white primaries. The under side of her wings instead of being white are light brown with darker markings. The speculum is obscured, apparently by being overlaid with black pigment. The bill is nearly black with greenish cast. The feet contain much black in addition to the normal orange. The occurrence of similar black ducks has been noted in two other flocks composed of Pekins and Rouens.

\section{THE $\mathrm{F}_{2}$ GENERATION}

The $\mathrm{F}_{2}$ generation is a motley assemblage. Unfortunately many of the young managed to lose their leg bands so that the exact parentage of each individual in not known. Consequently this generation will have to be considered as a whole, except in the case of pigmented and non-pigmented down, which is given in connection with the description of each mating. The adults are considered under a separate heading.

A record of the down plumage of each duckling was made at hatching time. The only correlation between down and adult plumage, about which there is no doubt, is that existing between yellow ducklings and white adults. There are several types of down among the pigmented ducklings, but their relation to the various types of pigmented adults is entirely unknown, so that the down records only enable us to separate pigmented from nonpigmented individuals.

$F_{2}$ matings and down color. Two pens of $\mathrm{F}_{1}$ were mated. In one a drake from a Pekin female by Rouen male was placed with two of his sisters. Their eggs did not hatch well and only nine young were produced. Six had pigmented down and three yellow down.

In the other pen was placed a drake, derived from a Rouen mother and Pekin father, with one of his sisters and the $F_{1}$ black duck with white breast. From the first duck there were five pigmented and four yellow ducklings; from the black duck there were seven pigmented and three yellow ducklings.

Altogether there were twenty-nine $\mathrm{F}_{2}$ ducklings from these two pens, nineteen were pigmented and ten yellow. If the black 
duck's progeny is left out of consideration there are twelve pigmented and seven yellow ducklings. In any case there is a considerable excess of yellow ducklings, the proportion standing about two pigmented to one yellow, instead of the expected ratio of three to one.

Later in the season, a Pekin drake was substituted for the hybrid drake in the second pen. There were seven pigmented and three yellow ducklings. Only one was reared, a male. He is not included in the table given below.

A mating was also made between a hybrid male and a Pekin female. Only three ducklings were hatched, two pigmented and one yellow.

$F_{2}$ adults. The chief interest in the $\mathrm{F}_{2}$ adults attaches to the pigmented types, which numbered twenty-one individuals, thirteen females and eight males. The white adults are identical with the Pekins. The distribution among the pigmented adults of the various characters studied are given in tables 1 and 2 . But there are also some points which require a more extended treatment.

Two females (fig. 7) and one male were essentially like the $\mathrm{F}_{1}$ black female, though the male and one of the females had a small amount of white, distributed irregularly on the head and neck. This last female retained her leg band. Her mother proves to be the black $\mathrm{F}_{1}$ female and her father a hybrid male. The black male has no white neck ring, no white primaries and no vermiculations. His is the only case in which these characters have been found absent in the male. His head, where not white, is lustrous green as in normal Rouen males.

The other eighteen individuals, show mostly Rouen characters. In one male the claret of the breast is wanting, its place being taken by iron gray (fig. 8). The speculum of this male is obscured and the under side of the wings pigmented. The rest of the males are not markedly different from the $F_{1}$ males, except that the width of the neck ring varies considerably.

Two of the females are much marked with white (fig. 9). The neck ring extends over nearly one-half the neck and reaches up the throat to the lower mandible. There is a large white patch 


\section{PLATE 1}

\section{EXPLANATION OF FIGURES}

1 Pekin male. $\times$ about $1 / 10$. The female is practically the same.

2 Rouen, male. $\times$ about $1 / 7$.

3 Rouen, female. $\times$ about $1 / 8$.

4 A, striped head. $\times$ about $2 / 7$; B, plain head. $\times$ about $1 / 3$. 
STUDIES ON HYBRIDIDUCKS H. D. GOODAI.E
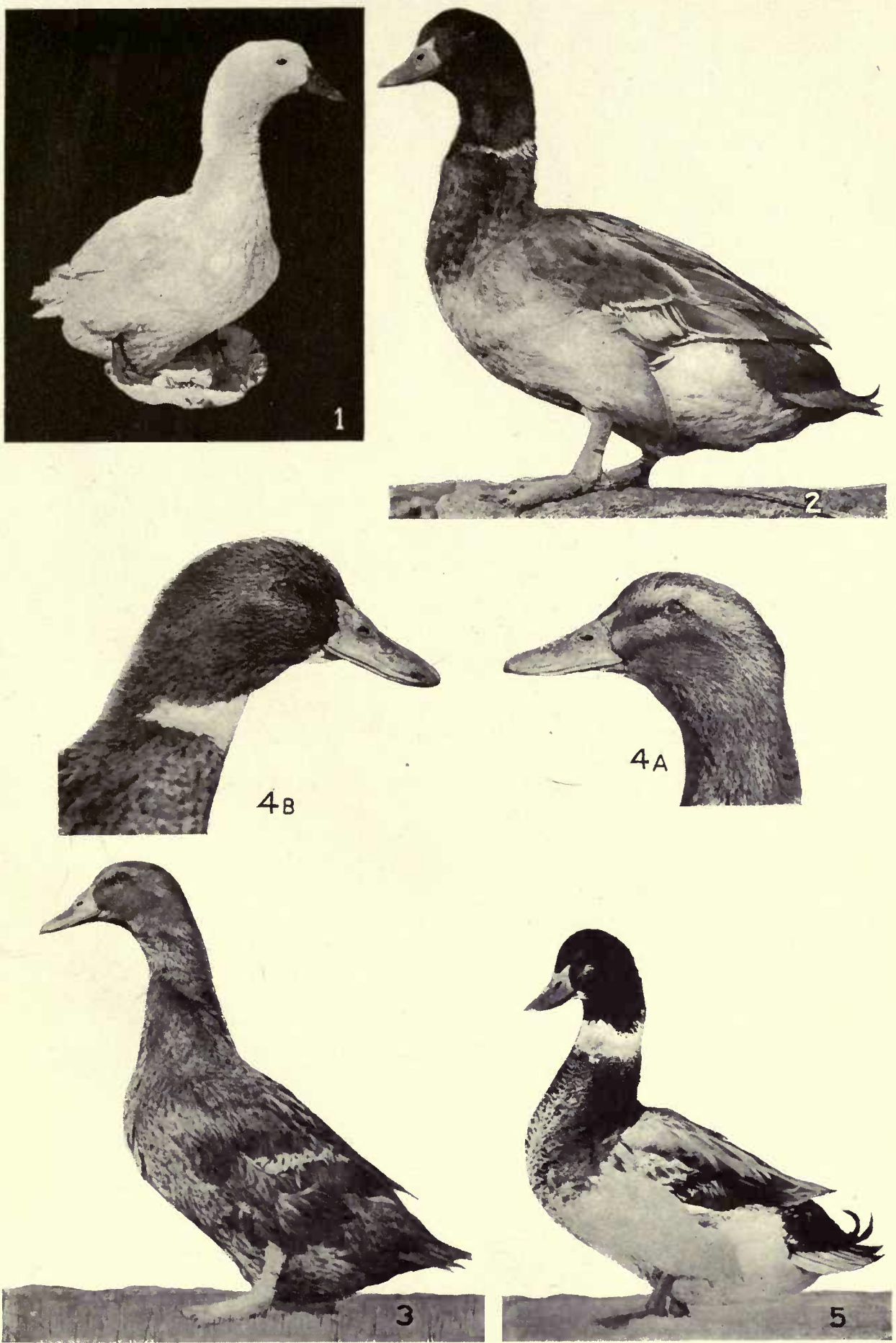

THE JOURNAL OF EXPERIMENTAL ZOÖLOGY, VOL. 10 , NO, 3 
PLATE 2

EXPLANATION OF FIGURES

$5 \quad \mathrm{~F}_{1}$ hybrid male. $\times$ about $1 / 10$.

$6 \quad \mathrm{~F}_{1}$ hybrid female. $\times$ about $1 / 7$.

$7 \quad \mathrm{~F}_{2}$ white breasted, black female. $\quad \times$ about $1 / 8$. The $\mathrm{F}_{1}$ black female is practically identical with this one.

$8 \quad \mathrm{~F}_{2}$ male which lacks the claret breast. $\quad \times$ about $1 / 7$.

$9 \quad \mathrm{~F}_{2}$ female, $\times$ about $1 / 9$, with much white and somewhat resembling an Indian Runner duck. 


$$
13
$$


on the belly and much white in the wings. Judging from a study of the other females, there are four points or centers for the origin of these white areas, viz.: At base of lower mandible, neck ring, posterior end of sternum and outer primaries. The white areas themselves may be large or small. They may all be present or all absent, or part may be present and part absent. In the case of the two females under consideration, all are present and all large, thus producing an effect which calls to mind the pattern of Indian Runner ducks. Both these ducks have nearly yellow bills.

One female has a noticeably redder breast than the others. Its meaning is uncertain.

There appears to be a curious correlation between plain head (fig. 4B) (i.e., head without stripes), obscured speculum and pigmented under surface of the wing. There are four cases of plain head among the females, not including the black individuals, two in $\mathrm{F}_{1}$ and two in $\mathrm{F}_{2}$. All had obscured specula and all had the under side of the wing pigmented. All the blacks have obscured specula and the under surface of the wing pigmented, though it is difficult to determine whether or not the head is really striped.

\section{DISCUSSION}

The data which I have been able to present are too meagre to permit of much discusision. There are, nevertheless, some features which are strongly suggestive.

The most striking thing about the $F_{1}$ generation is the apparently greater heterogeneity of the females as compared with the more homogeneous males. A description of one $\mathrm{F}_{1}$ male would fit all the other $\mathrm{F}_{1}$ males, though, of course, larger numbers might prove this statement to be without foundation. The evidence in regard to certain characters is, however, fairly strong. 'All $\mathrm{F}_{1}$ males have a white neck ring and white primaries. Further, leaving out of consideration for the present the summer plumage, no case of striped head has been seen in the $F_{1}$ males. There is similar but less conclusive evidence in regard to some other characters. But there is no evidence of an opposite nature. Since in 
$F_{1}$ certain characters are present in some females and absent in others, and since in the males the same characters are always present (or always absent according to the character in question) it appears that these characters are sex limited. The following generalized formula will show how the facts may be interpreted, using Bateson's assumption of a sex homozygous male and sexheterozygous female.

$\mathrm{S}$, is a sex limited character; s, its absence, $i . e$ : the presence of another character. The $\mathrm{P}_{1}$ females are $\mathrm{S} \& \mathrm{~S} \sigma^{7}$; the males $\mathrm{S} \sigma^{7}$ $\mathrm{s} \mathrm{o}^{\mathrm{r}}$. Coupling is assumed to occur between $\&$ and $\mathrm{s}$. Or, if prefered, a repulsion between $q$ and $S$ may be assumed, or a coupling between $\sigma^{x}$ and $\mathrm{S}$. The $\mathrm{F}_{1}$ then, will be $\mathrm{S} \sigma^{x} \mathrm{~S} \sigma^{x}, \mathrm{~S} \sigma^{x}$ $\mathrm{S} 0^{x} ; \mathrm{S} o^{x} \mathrm{~S}$ \% , $\mathrm{S} 0^{x} \mathrm{~S}$ o .

The $\mathrm{F}_{1}$ males, then, will be visibly alike, though of two gametic constitutions; the females will be of two visible classes.

Before going further, it may be well to point out that the data at hand do not necessarily support Bateson's theory, for the facts can also be represented thus;

Females $\mathrm{s} \% \mathrm{~S} \%$; Males $\mathrm{s} \odot \mathrm{S} \sigma^{7}$, giving females $\mathrm{s} q \mathrm{~s} q, \mathrm{~S} q$ $\mathrm{S} \%$ and males $\mathrm{S} \sigma^{x} \mathrm{~S} \%, \mathrm{~S} \sigma^{\rightarrow} \mathrm{S} \%$.

Random matings of the $F_{1}$ will give theoretical results in $F_{2}$ agreeing sufficiently well with the observed results, which ever formula is used, though according to the first method of formulation, a few males should occur without the character in question in $F_{2}$. According to the second method all the $F_{2}$ males should have the character in question. The $\mathrm{F}_{2}$ black male lacks a ring neck and white primaries, thus rather favoring the first mode of representation. However, it will probably be necessary to establish suitable strains, before the bearing of the experiments on the present theories of sex determination becomes perfectly clear, but the experiments indicate unmistakably the existence of some sort of sex limited inheritance with respect to several of the characters studied.

In the formula given above I have assumed that both sexes of the parent stock were heterozygous for certain characters. I have made this assumption because of the variety of forms appearing in $\mathrm{F}_{1}$ which ordinarily conforms to a single type. The unex- 
pected occurrence of such characters as a broad neck ring in the males and the appearance of a neck ring, plain head and black individuals among the females, is probably due to the presence of cryptomeres in the Pekins, though this point cannot be proved until further crosses with other varieties of ducks are made. Ridgeway, however, mentions in passing a cross between Muscovy• (black) and Aylesbury (white). The progeny were colored like mallards. His figure shows a very broad neck ring.

Thus, in many respects $F_{1}$ in the present instance, is like an $F_{2}$ generation. The $\mathrm{F}_{2}$ generation in these experiments contains only a few more forms than $F_{1}$. Indeed, with larger numbers, some of the forms which have appeared only in $\mathrm{F}_{2}$ may reasonably be expected to appear in $\mathrm{F}_{1}$. A priori, it would seem more probable that the heterozygous males occurred among the Pekins. The Pekins may easily be a mixed population in respect to numerous factors rendered invisible by the white plumage. Some individuals may be heterozygous in respect to a given character while others may be homozygous either for the presence of this character or for its absence. The introduction of color has made possible the isolation of pure lines.

As the individual mothers of the $F_{1}$ generation are unknown, it is obvious that if one mother were homozygous for a character and another heterozygous, the father being homozygous, that the observed results would follow, provided that it is also assumed that in the female a character does not become patent except in the homozygous condition, though patent in its heterozygous condition in the males. Thus the case would be paralleled to the inheritance of horns in sheep, cited by Bateson.

Not all characters appear to be correlated with sex. White shading of the breast and red-white on the dorsal wing surface is present in some $F_{1}$ individuals of both sexes, absent in others, thus behaving as if it were of the form DR in both parent stocks, or DR in one and RR in the other. The evidence, however, is conclusive that at least one of the parent stocks contains individuals which are heterozygous for certain characters. 




































































$=$ 





THIS BOOK IS DUE ON THE LAST DATE STAMPED BELOW

AN INITIAL FINE OF 25 CENTS WILL.BE ASSESSED FOR FAILURE TO RETURN THIS BOOK ON THE DATE DUE. THE PENALTY WILL INCREASE TO 50 CENTS ON THE FOURTH DAY AND TO $\$ 1.00$ ON THE SEVENTH DAY OVERDUE.

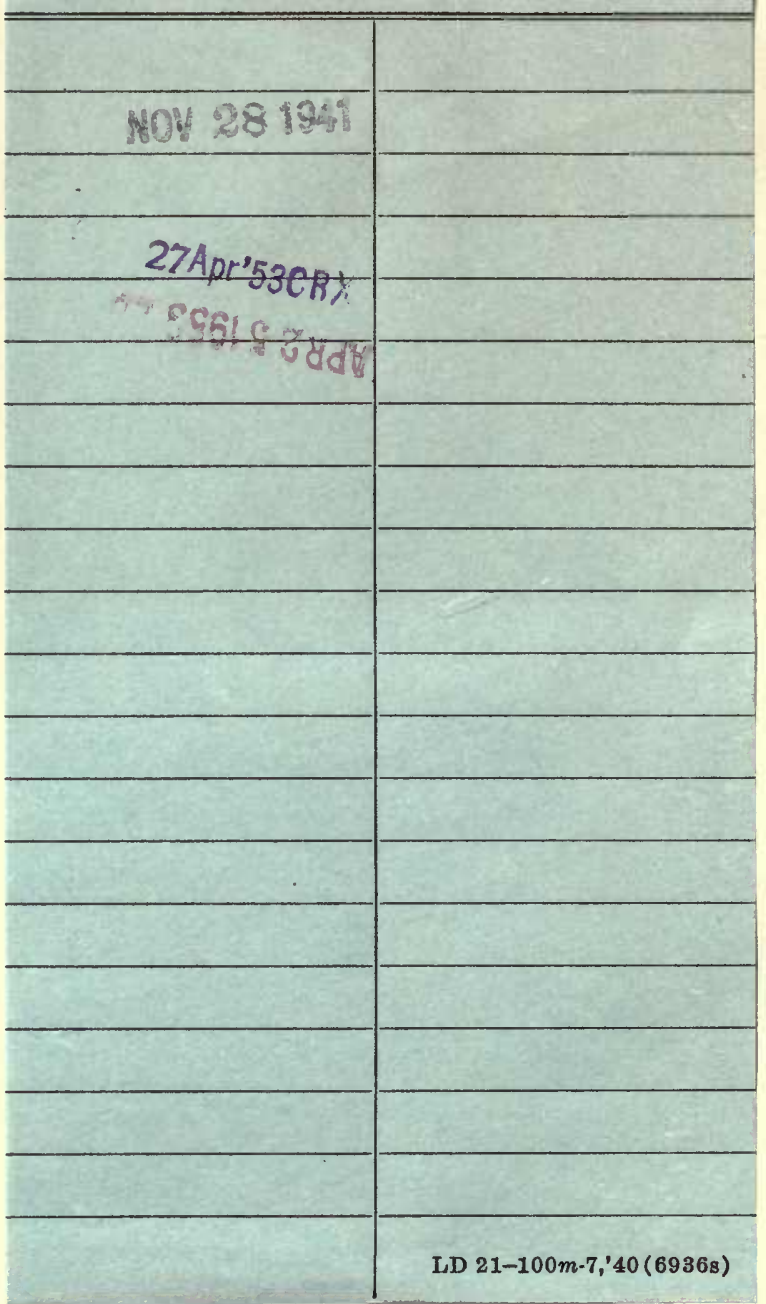




\section{9}

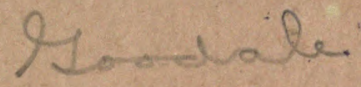

$\frac{6}{6}$
$\frac{1}{2}$
$\frac{2}{5}$

UNIVERSITY OF CALIFORNIA LIBRARY 
